Clark, Jessica P. "'Will You Give Me Your Opinion?': Mundane Beauty in the Englishwoman's Domestic Magazine, 1860-75." Victorian Periodicals Review 52, no. 3 (2019): 540-

565. doi:10.1353/vpr.2019.0034.

\title{
"Will You Give me Your Opinion?": Mundane Beauty in the Englishwoman's Domestic
}

\section{Magazine, 1860-75}

\section{JESSICA P. CLARK}

In February 1868 the Englishwoman's Domestic Magazine printed a letter enquiring about experiences with hair treatments. Correspondent C. M. R. requested advice from readers of the "Englishwoman's Conversazione" on a widely available commercial hair restorer. On news that Mrs. Allen's Dressing caused itchy red scalps in two acquaintances, "I bethought," she wrote, "of your invaluable Conversazione, which so often helps us out of difficulties"; she felt "most thankful if any of your subscribers who may have used this preparation will kindly inform me whether the result was similar in their case." ${ }^{\prime 1}$ C. M. R.'s letter set off a chain of responses over the coming months, including a warning from respondent Constance that Mrs. Allen's Dressing contained hazardous amounts of mercury. Constance's disclosure in turn prompted a defensive response from the manufacturer, who asserted the "natural" makeup of his company's product and impugned Constance's motives. ${ }^{2}$ Other responses followed both refuting and supporting Constance's charge, accompanied by correspondents' own tried-and-true personal recipes for hair restorers.

Exchanges like that of C. M. R. and her contemporaries illuminate the role of the correspondence column as a textual community of participants, as defined by Margaret Beetham and Lynn Warren. The conversazione functioned as a textual forum where female interlocutors engaged in the production of personal and collective meanings. According to Beetham and 
Warren, columns could operate as relatively independent entities despite editorial attempts to manage their content, forging a sense of belonging to a discursive milieu populated by textual identities. $^{3}$ As part of this exchange, participants in the "Englishwoman's Conversazione" periodically debated daily practices of bodily management despite popular opprobrium of female beautification through the mid-nineteenth century. Indeed, in addition to questions about fashion and needlework, the column encouraged a widening circle of consumer knowledge encompassing a commercially conscious public sphere of citizens who debated the efficacy and, more importantly, the safety of widely available beauty products. Although C. M. R. reportedly discussed hair treatments with two friends, she relied on the larger community of the Englishwoman's Domestic Magazine's correspondents to substantiate their negative claims. She placed her trust in a textual community of women facilitated by the popular press in an effort to buttress traditional forms of advice shared among female intimates. Her effort bore fruit; it elicited Constance's response that exposed the dangerous chemical makeup of the hair product, a factor unbeknownst to C. M. R.’s unfortunate acquaintances.

C. M. R.'s letter, with its focus on health and beauty, appeared at a moment when the Englishwoman's Domestic Magazine was embroiled in a contentious and highly documented debate over corset training, first ignited in March 1867. In that same year another sensational correspondence emerged. This time the topic of corporal punishment eclipsed the tight-lacing debate in terms of length and public censure, adding further infamy to the conversazione. ${ }^{4}$ Historians of Victorian sexuality have fixed on these two correspondences as instances of what Mary Poovey terms "boundary work," a moment of ideological disjuncture that reveals conflicting expectations of female sexuality and desire. ${ }^{5}$ For some, like David Kunzle, the letters represent subcultural expressions of desire circulating in Victorian society. He argues that 
women adopted tight-lacing in its erotic context as a fetishized practice and not, as some earlier scholars attest, a symbol of subordination. ${ }^{6}$ For others, like Ros Ballaster, Margaret Beetham, Elizabeth Frazer, and Sandra Hebron, the correspondence about tight-lacing emerged in part because of editorial strategies that presented multiple, contradictory forms of femininity, situating female readers as domestic managers but also desirable women. Samuel Beeton, publisher of the Englishwoman's Domestic Magazine, bolstered readers' sense of desirability through his masculine "semi-flirtatious tone" when replying to readers' queries on love and romance. ${ }^{7}$ More recently, Beetham and Sharon Marcus shifted the discussion to consider the whipping and corset debates as complex expressions of female hetero- and homoerotic desire made widely available to women readers. ${ }^{8}$

With its suggestive glimpses into gendered and sexual subjectivities of Victorian reading publics, the Englishwoman's Domestic Magazine's explosive correspondence has attracted significant attention from leading scholars. This essay adds a new dimension to this scholarship by devoting careful attention to more mundane letters like C. M. R.'s, printed before and during the corset and whipping debates. While the sensational debates of 1867 represented a high point in the magazine's discourse around the female body, they emerged out of a longer tradition of more quotidian considerations of artificial cosmetic beautification. I argue that the structure of this mundane beauty correspondence as a public dialogue within a magazine column, as well as its thematic considerations of daily bodily management, provided a cultural frame and repertoire for the more extraordinary tight-lacing and whipping debates. The mundane exchanges therefore deserve scholarly attention in their own right, as they established a discursive space out of which the sensational correspondence developed. 
In her germinal work, Beetham situates the correspondence column as a forum of conversation in which female interlocutors produced shared notions of selfhood, relying on a discursive print culture to foster a sense of collective identity. Through the "Englishwoman's Conversazione," contributors came to understand themselves in terms of class, nationality, and gender as "middle-class Englishwomen." The conversazione was a textual form of liberalism writ small, a self-regulating society of women operating under a code of conduct upheld by fellow correspondents (with periodic editorial intervention). These were not passive readers coerced by authoritative discourses. Rather, correspondents were active participants in a liberal forum enabled by an expanding consumer culture and middle-class mass market. ${ }^{10}$ This consumer culture merged with elements of a broadly defined medical marketplace to shape correspondents' technologies of the self. Through discourses of bodily self-fashioning, correspondents articulated a form of female eroticism marked by anxiety, pleasure, and conflict.

Central to this articulation was a shared "textual identity," to use Warren's term, that engendered a sense of trust among readers of ostensibly similar class and gender positions. ${ }^{11}$ Collective trust was particularly important in discussions of bodily management, which pushed the bounds of respectability despite new commercial developments. At the mid-nineteenth century a rise in artificial beautification —including the use of rouge, depilatories, hair dyes, and tonics - challenged dominant expectations of "natural" feminine beauty. This shift was propelled through the 1860 s by a burgeoning commercial beauty industry that encouraged female consumers to purchase rather than self-produce beautifying goods. Letters to the “Englishwoman's Conversazione" highlight this moment, revealing how women navigated tensions between traditional and commercial beauty products as well as artificial and natural aesthetics. As my analysis demonstrates, the conversazione was integral to this shifting 
landscape of beautification because it expanded the possibilities for textual considerations of the female body, to explosive effect.

\section{Nature, Artifice, and the Englishwoman's Domestic Magazine}

The Englishwoman's Domestic Magazine was a novel addition to mid-nineteenth-century print culture. Eighteenth-century publications for women had established opportunities for female readers to engage in new forums of exchange tailored to their desires and needs. By the nineteenth century, as Roz Ballaster and others have shown, publications became important sites of pleasure and contestation, forums through which feminine identities were negotiated, debated, but never fixed. ${ }^{12}$ Indeed, content was often riddled with tensions and contradictions in the multiple definitions of femininity advanced in magazine pages. ${ }^{13}$ These processes of identity formation related not only to gender but also class. ${ }^{14}$ Print media for middle-class women was only beginning to proliferate when the Englishwoman's Domestic Magazine first appeared in 1852, as the growing interest in female consumption opened a new market for periodical publishers. ${ }^{15}$ Samuel Beeton and his wife Isabella established the magazine to appeal specifically to the increasingly prosperous lower middle classes as a class-appropriate alternative to elite fashion magazines dominating the market. ${ }^{16}$ In doing so, they joined approximately fifty-seven women's magazines in publication at various points between 1860 and 1872 . In terms of expense, publications ranged from one shilling sixpence for the upper-level fashion monthlies (due in part to the number of expensive color plates and patterns) down to a halfpenny for weekly miscellanies. At a cost of twopence, the Englishwoman's Domestic Magazine initially positioned itself in the center of the price range, although the price increased to sixpence with editorial changes of 1866 . It was the only publication in its price bracket to offer considerations of both home and fashion, thus making it a standout among that class of women's magazines. 
Beyond price, the content of the magazine also reflected the Beetons' targeting of what they considered an aspiring middle-class readership of "countrywomen already initiated in the secret of making 'happy home." ${ }^{\prime 17}$ When the Beetons' publication appeared on the market, competitors in the same price bracket tended to concentrate on topics relevant to more elite interests, such as the events and seasonal activities of the ruling classes. ${ }^{18}$ By contrast, the content of the Englishwoman's Domestic Magazine emphasized thrift, industry, and usefulness, in deference to utilitarian thought informing middling economic groups of the mid-nineteenth century. ${ }^{19}$ Historians argue that this middling group enjoyed considerable economic prosperity in the third quarter of the nineteenth century; from 1851 to 1901 , the average income per person doubled among middle-class Britons. ${ }^{20}$ The Beetons thus tapped into an increasingly selfdefining and affluent populace who used their growing disposable income to express a particular middle-class ideology. ${ }^{21}$ By addressing reciprocal interests of virtue and consumption, the Englishwoman's Domestic Magazine stepped into a void and garnered excellent circulation from its first appearance, reaching approximately 50,000 copies just seven years after its launch. ${ }^{22}$ In courting their readership, the Beetons engaged with a domestic feminine ideology already prevalent in the cultural imagination, which conferred symbolic authority on women as embodiments of purity and sexual ignorance but also competence and practicality. ${ }^{23}$ These cultural conceptions also situated middle-class women as guardians of social values and class boundaries. Such messages circulated across a number of print forums of the time, including popular didactic manuals that privileged the maternal body as the site of moral, middle-class womanhood. ${ }^{24}$ Publications such as The Mother's Thorough Resource-Book (1860) and The Mother's Medical Advisor \& Guide for Emergencies (1862) offered an array of advice for the care of husbands, children, and sometimes women themselves. These health manuals often 
derided women's frivolous pursuits of beauty and their detrimental effect on reproductive capabilities. Pye Henry Chavasse, for one, deemed fashion to be "another name for suicide and baby-slaughter-for 'massacre of the innocents!" ${ }^{25} \mathrm{He}$ subsequently devoted the first third of his Advice to a Wife (1868) to admonishing readers for their "artificial" lifestyles and criticizing excessive socializing, sedentary habits, and the resistance to "natural" maternal urges. Chavasse was by no means an anomaly among physician-authors writing for middle-class women. Health authors vocally condemned frivolous practices, including modification and bodily restraint for the sake of beauty. ${ }^{26}$

Although the Beetons endorsed women as domestic managers and moral exemplars, they also embraced fashionable activities at odds with a feminine ideal of naturalness and maternal self-sacrifice. The editors were in competition with fashionable lady's magazines that advocated the very activities denigrated by Chavasse and other health guide authors, and a substantial part of the Englishwoman's Domestic Magazine's market appeal depended on purveying fashion geared toward middle-market incomes. The Beetons therefore encouraged some practices that physician-authors deemed injurious to middle-class women even as they discouraged others. Consequently, their publication duplicated tensions over "healthy" lifestyles by encouraging practices that were disparaged in these didactic guides. ${ }^{27}$ For example, Beeton acknowledged the health hazards of certain items of restraining clothing. Of corsets, he noted that "the intermeddlings of the staymaker" had "often spoiled a girl's figure and fortune., ${ }^{, 2}$ Part of the magazine's appeal, however, hinged on depicting such fashions. So while Beeton gestured toward accommodating health guides' principles, he in no way positioned himself as the enemy of fashion in the manner of Chavasse and others. 
Crafting the fashionable female reader concerned not only the toilette but also the body itself. Despite popular censure of artificial beautification, the Englishwoman's Domestic Magazine periodically suggested that beauty was not only desirable but also attainable through discreet interventions. For instance, the 1866 series "The Human Form Divine" established specific aesthetic standards for the form and figure of the eyes, skin, and other features. According to the author, the ideal nose took a "Grecian" form, "one of the most beautiful that was ever chiselled," and was free from a "red tip ... a matter of sore distress to many ladies quite innocent of shrewishness or of grape worship. ${ }^{29}$ While features like the nose were not easily transformed, other qualities could be subject to artificial beautification. In a subsequent column, the author observed that "all the best things of Nature have their fraudulent representatives in Art," and this included women's hair: "When the hair is thin, Art thickens it," he argued, "when it is grey, turns it to black; when it is this, turns it to t'other; when there is none of it or little of it, supplies a luxuriant crop in the shape of a wig" (figure 1) ${ }^{30}$ Nature did not bestow beauty upon all, and women could turn to art—or artifice— - to remedy bodily defects.

Although the pursuit of beauty via technologies of the self required caution, a subsequent series did little to clarify the tensions between nature and artifice. "Health and Beauty" opened in January 1867 with four installments devoted to the care of children, reminding readers first and foremost of the duties of the reproductive, maternal body. The series then transitioned into fifteen segments devoted to hair, including its structure, color, shape, length, and uses. ${ }^{31}$ As in the previous series, tensions between nature and artifice underpinned more quotidian considerations, such as etiquette at the hairdresser's or selecting the optimal hairbrush. At one point, the column acknowledged the increasingly widespread use of artificial means to attain beauty. Initially echoing contemporary didactic authors, the author advocated exercise and 
abstemious living over artificial manipulation in the name of beauty: "It seems a degrading thing to regard the fair sex, which is so calculated to bestow and encourage all that is refined and pure, as a mere object of sense and sight - a show or puppet. But some have said, strip ladies to-day of their paint, power, false hair and teeth, cosmetics and artificial appliances, and then how should we criticise the remainder?" ${ }^{32}$ Here, the author supports a domestic ideological view of women as naturally "refined and pure" and suggests that beauty practices merely accentuated the falseness and artificiality of the era. Like many health advisors, the author warned that a woman who used cosmetics transformed herself into an objectified "puppet" rather than the active manager of middle-class morality.

Despite this warning to readers to repent their artificial ways, the very same column allowed for some participation in commercial beautification, albeit with care. "Ornamentation... does in itself no very great harm," wrote the author. "I3 "It may, indeed, be but the tell-tale of vice and vanity; it may, on the other hand, show that Nature can be helped by Art." ${ }^{\prime 34}$ In other words, artificial adornment was possible, but only if women exercised restraint, "seizing the happy medium. ${ }^{, 35}$ These subtle interventions could be achieved through new commercial beauty options available to women shoppers: "bottles innumerable, devices without end, artificial hair of all shades, kinds, and colours, powders, applications, [and] designs. ${ }^{36}$ In acknowledging the possibility of tasteful artifice, the author allowed for a measured solicitation of new beauty products increasingly available to his readers. This also meant, however, that the magazine circulated mixed messages about the respectability of beautification, reflecting the "simultaneity" that defined considerations of Victorian beauty culture, as Rebecca Kling has shown. ${ }^{37}$ The relationship of nature to art remained fraught, and discussions of beauty in the Englishwoman's Domestic Magazine failed to diffuse these tensions, not to mention those 
regulating the purchase of beauty wares. It was here that the conversazione, with its direct line to feminine knowledge and expertise, came to the fore.

\section{Mundane Beauty in the "Conversazione"}

As health and beauty articles circulated conflicting messages on nature versus artifice, Beetham argues that the correspondence columns emerged as a site to negotiate multiple positions about female self-fashioning, whether at home or in the commercial sphere. Judging by their expanding length through the mid-nineteenth century, the Englishwoman's Domestic Magazine's two distinct correspondence columns were extremely popular among readers; however, by 1867 the popularity of the "Englishwoman's Conversazione" morphed into notoriety as attention turned to sensational topics of bodily management and, more specifically, corset training and whipping. ${ }^{38}$

As we will see, the sensational debates of 1867 certainly indicate that competing notions of femininity and feminine self-fashioning circulated in the correspondence columns of the Englishwoman's Domestic Magazine, as Beetham and others have argued. ${ }^{39}$ However, this was not the only case where bodily negotiations transpired in the conversazione; letters on ordinary, commonplace questions of beauty and health also betray correspondents' attempts to define their relationship to bodily management, including commercial interventions. The sensational correspondence did not surface unexpectedly but instead gradually emerged out of conversations already underway on mundane matters of beauty and health. Well before the tight-lacing and whipping debates, the correspondence column was a forum for sorting out contradictory messages about the material body, albeit in a more quotidian form. Correspondents interacted with others by questioning, resisting, or reconfiguring perceptions of the feminine body and the growing consumer products related to the hair, skin, and face. This process continued throughout 
the sensational correspondences, operating in tandem with spirited debates over corsets and birch rods.

Before 1855 the Englishwoman's Domestic Magazine featured two correspondence columns, each serving a distinct purpose for its readers. "Cupid's Letter Bag" fielded questions of love and romance, particularly correspondents' concerns about their inability to find a suitable husband. By contrast, the "Englishwoman's Conversazione" fielded queries on health, domestic management, and social etiquette. Letters addressed topics such as the preparation of a dinner à la Russe or suitable books for boys. ${ }^{40}$ When the columns were combined under the conversazione title, concerns of love, domesticity, and the body collapsed into a shared forum of exchange. ${ }^{41}$ Throughout, Samuel Beeton's encouraging responses were surely appealing to many discouraged correspondents who were anxious about their unmarried status or imperfect domestic skills, and according to Beetham, a "confessional" quality pervaded many correspondent narratives. ${ }^{42}$ Beeton himself encouraged this, demanding that correspondents include bona fide return addresses while readily accepting noms de plume. The pages of his magazine thus offered women a forum to freely express companionate desires and bodily dissatisfaction while exploiting the relative anonymity of the new print culture.

As such a forum, the Englishwoman's Domestic Magazine was notable because its correspondence columns operated according to different rules than those of competing women's periodicals. The columns in the elite fashion publication the Queen, for example, considered correspondent queries in the "Answers" column on topics like "Cleaning the Teeth" and "Lip Salve." ${ }^{43}$ Between 1863 and 1864, this extended into a brief discussion of corsets, but it was seemingly halted for the sake of decorum. By 1875 , however, a new set of rules prohibited "queries related to medical and surgical topics ... [or] . . to merely personal or private matters, 
to frivolous fancies. ${ }^{, 44}$ When correspondents seemingly continued to submit such questions, the Queen's editor noted that "in future, questions for preparations for the hair must be attended by a stamped and addressed envelope, as the replies, if any, will not be printed, but forwarded by post"; he concluded this warning with the notice that "hair dyes and depilatories [were] rigorously excluded. ${ }^{, 45}$ Instead, correspondents traded patterns and fashion advice, recipes, and rules of etiquette, but they were prohibited from airing concerns of health and the body (or “merely personal or private matters").

By contrast, Beeton's publication of beauty questions allowed female correspondents to fret about troubling issues of appearance without fear of being accused of vanity, as in popular health guides. As a result, readers increasingly posed questions that combined issues of (sexual) attractiveness and domestic practice in the guise of letters on personal remedies for cosmetic problems. Beeton's openness made the convesazione especially prized by readers, who seemed to appreciate the ability to divulge information without risking embarrassment. As a contributor named Annie Black noted, correspondents "seem so kind—quite like an experienced friend," before asking, "will you give me your opinion?"46 The subsequent deluge of letters, quipped the editor, suggested that "nobody is satisfied" with their appearance. ${ }^{47}$

Despite his involvement, however, Beeton did not reply to all letters in the column, leaving many questions for readers to answer amongst themselves. Writing about women's magazines in the late nineteenth century, Warren has shown the frequency of these two styles of correspondence: the first, "featuring the 'voice' of the reader, with or without editorial comment," and the second, "consisting solely of the editorial "voice.",48 In the former style, contributors responded to particular questions and provided their own solutions, advice, and remedies. The responses often included personal testimony to establish solidarity between the 
advice-giver and the original correspondent. The column thus functioned as a discursive network much along the lines of traditional friendship and domestic relations. Correspondents received advice, however, from an anonymous community of contributors rather than from female neighbors. What made this advice acceptable was the participants' seemingly shared values and social milieu. After 1867 Beeton encouraged this type of reader-to-reader exchange to "impart to our Conversazione pages renewed interest. ${ }^{49}$ From January of that year, Beeton consciously devoted a section of the column "to those who have ... any question to submit on which it is desirable that the opinion of other ladies should be taken. ${ }^{, 50}$ While there were some examples of reader response prior to 1867 , Beeton standardized the forum of exchange with his proposal. Correspondents subsequently pursued threads that were of personal interest, not to mention exercised increased control over the topics of discussion.

Through the 1860s this included women's disclosure of highly private aesthetic concerns to other readers. Bodily questions featured in over 60 percent of conversazione columns from July 1860 onward, when a reader first enquired about a recipe for rouge.$^{51}$ Frequent topics of conversation included hair removal (which "perplexes a large number of our fair friends"), weight loss, sunburns, chilblains, and the lengthening of eyelashes. ${ }^{52}$ By March 1868, in the midst of both the tight-lacing and whipping letters, Leonora enquired "how to cure little pimples on the forehead and chin" and "what can make her arms so red when they are uncovered for a ball, and how to make them white." ${ }^{, 53}$ Meanwhile, Esmeralda asked readers' opinions on different depilatories, for which she was willing to trade "a very good recipe for the cure of corns. ${ }^{, 54}$ She wrote to her imagined audience, "I think we might help each other very much in this way." 55 In the next edition, a correspondent who signed herself "An Englishwoman" described "two large places on [her] head [that were] perfectly bare" from wearing frisettes, a 
gathering of artificial curls, and requested advice on stimulating hair growth. ${ }^{56}$ Meanwhile, another asked for guidance on removing "50 small warts on the back of her hand."57

These correspondents considered the body a site of change and manipulation, yet in spite of their interest, bodily descriptions remained brief and to the point. Christabelle, for example, posed three questions about the body in the form of a list, demanding "what is the best soap to use for the complexion? what is the price? and where can it be obtained?" ${ }^{58}$ She offered no description of her own complexion, focusing instead on utilitarian concerns of cost and purveyor. The aforementioned Annie Black inquired about "a natural fleshy enlargement on [her] chest," a point of "great annoyance" for her. ${ }^{59}$ She made no effort to describe either the growth or the nature of her displeasure (be it pain or unsightliness) and moved quickly onto her next question of whether "walking reddens the face, or makes it glow still more?" ${ }^{60}$ Such authorial reticence may derive from a number of sources. It is possible that correspondents offered only generalized descriptions of the body to retain an important degree of remove, thereby maintaining decorum; alternatively, correspondents may have emulated the overly general advice available in health and beauty guides of the era or aligned themselves with the "nondescript woman depicted in fashion plates," as described by Kathryn Ledbetter. ${ }^{61}$ The minimally described body nonetheless figured as malleable and controllable, capable of being transformed if one could ascertain from others an effective technique.

Although terse, these descriptions of bodily aesthetics and manipulation betrayed women's earnest concerns as they negotiated the level of risk involved in conforming to reigning standards of appearance. To increase their attractiveness, correspondents inquired about cosmetic practices involving chemical treatments and preparations. Given the risky nature of chemical treatments, however, health became an implicit consideration in many of the requests. Women 
mixed dyes, powders, and ointments replete with chemicals and potentially damaging effects. A letter signed "More Hair Dye" reveals that women worked with ingredients like sulphur, as it would not dissolve in her homemade colorant. She subsequently wrote, "Your August number gives a receipt for hair-dye. . . . Since printing the above, have you tested it?"62 Another reader suggested a cure for chilblains containing "[h]ydrochloric acid, diluted, 1/4 ounce; hydrocyanic acid, diluted, 30 drops; camphor-water, 6 ounces" before warning "it is a deadly poison, and should be kept under lock and key."

A further ambiguity surfaced around the administration of the treatments, gesturing again to the risky nature of home-produced cosmetics. Following a letter to the conversazione about a skin treatment, Maggie P. enquired about "the manner of applying the cosmetic, whether as a wash or to be drunk?" ${ }^{\prime 64}$ This was not the first time a correspondent asked for such clarification, as another writer made the very same request some six years earlier in December $1860 .^{65}$ As the questions implied, concocting one's own cosmetics could be a difficult process, which often required advice and clarification from others engaged in similar activities. Such interests also suggested correspondents' limited economic and social status in demanding recipes that were low cost and easy to produce in one's own home. ${ }^{66}$

Despite correspondents' pursuit of the least damaging means of achieving desired results, outcomes were often detrimental and unexpected. The conversazione functioned as a means of determining the efficacy and safety of these concoctions, a virtual testing ground for the latest hair dye and face cleanser. "Lady Jane," for one, asked, "Can any of your numerous correspondents tell me of any harmless lotion to remove slight small-pox marks?" ${ }^{97}$ Beeton remained distantly involved throughout this exchange, at one point reminding readers "every woman has the remedy in her own hands. If she feels the practice to be an injury to her, she can 
but discontinue it at any time. ${ }^{968}$ While he would comment on letters of love and courtship, he usually left questions of the female body for other correspondents to consider.

Letters indicate that correspondents emphatically desired to alter their appearance, regardless of the potential dangers and health consequences. Correspondents often recounted beauty horror stories revealing the lengths they would go to increase attractiveness. H. W., for instance, described how her "hair came off," but now "few ha[d] thicker hair than" she. ${ }^{69}$ She subsequently offered to send a sample of her miracle hair-growth treatment for the initial correspondent Hibernia to try herself. Returning to the query that opened this essay, Constance responded to the communiqué by C. M. R. about hair dye: "With regard to Mrs. Allen's Restorer, I do not think any one ought to use it that has ever taken mercury, as I myself was introduced to try it, and upon the second application found my teeth loose, and mouth very sore and very much swollen; in fact I was obliged to have advice. I took a little of the Restorer in a bottle to a chemist, to ascertain if it was the cause of my complaint, when he told me it contained the bichloride of mercury, which certainly was the cause of my teeth feeling loose. ${ }^{, 70}$ In spite of her unpleasant experience, Constance concluded her letter by noting, "I should feel obliged if any one having tried the Constant Subscriber's remedy, will, in your 'Conversazione,' let me know the effect it had on her hair, and whether it was a Dye or Restorer." ${ }^{\text {"71 }}$ Constance's strong desire to color her hair overrode fears of further mercury poisoning or limitless other forms of health damage.

The debate did not close, however, with Constance's response. In the following edition John M. Richards, proclaimed distributor of Mrs. Allen's World's Hair Restorer, wrote to dispute Constance's account and accused her of trying to tarnish the commercial image of "Mrs. Allen." He could not disclose the restorer's ingredients as "[t]he recipe, like that of all 
proprietary articles, represents capital, and belongs only to the proprietor of the trademark, and cannot, of course, be made public., ${ }^{, 2} \mathrm{He}$ implored readers to trust that the concoction was of natural origins, relying on oppositions between nature and artifice already circulating in the column.

To be sure, the growing influence of consumer beauty culture is apparent in these discussions (figure 2). As Jeffrey Auerbach argues, women's magazines were not only products but also themselves "producers of an ethic of consumption." ${ }^{, 73}$ This was especially the case in domestic magazines, notes Jennifer Phegley, which educated women "to be proper consumers of products. ${ }^{, 74}$ This extended to beauty consumption, and some advice on engaging in selfmodification in the name of beauty involved purchasing various products rather than concocting them at home. Kay Boardman has noted a degree of complicity on the part of the Englishwoman's Domestic Magazine's editors in promoting specific goods in their responses, thus transforming the column into yet another forum for commercial promotion. ${ }^{75}$ Yet readers did not accept this advice uncritically, and the conversazione also functioned as a place to review commercial products promising specific results. As we have seen, Mrs. Allen's Dressing was a topic of particular concern given its mercurial composition. "A Dentist" added his opinion to an exchange on the efficacies of dentifrices, decrying the use of charcoal in lieu of commercial dentifrices like Condy's Fluid. ${ }^{76}$ As usual, Beeton encouraged readers to determine their personal preference, noting, "We insert this letter that our readers may judge for themselves," but he added that, in his experience, "Bragg's pure carbon . . . is highly beneficial to the teeth." was not the first time the editor promoted a particular commercial brand, and references to goods like Eugène Rimmel's Perfumed Powder and Alexander Ross' Hair Destroyer also appeared. ${ }^{78}$ However, it was ultimately left to the reader to determine the product best suited to her needs, in 
keeping with the liberal underpinnings of the column. Such discussions of consumables paralleled the rise of standardized, commercial patent products and beautifying goods pitched increasingly to middle-class women. ${ }^{79}$

Debates over hair dyes and rouge reveal correspondents' attempts to work within the expected parameters of middle-class respectability while maintaining a particular standard of feminine beauty. Middle-class correspondents used the conversazione to rationalize artificial beauty aids and bodily manipulation in the face of popular rhetoric decrying such techniques. By sharing their recipes for and reviews of hair dyes, correspondents sought affirmation from others who valued the fabrication of beauty while subscribing to a similar mode of middle-class, female Englishness.

\section{The Conversazione Controversies}

In the midst of queries about hair dyes and dentifrices, two debates emerged that surpassed all others in terms of public interest, duration, and sensationalism: the correspondences on tightlacing and whipping. The tight-lacing debate was the more protracted of the two, extending from 1867 to 1877 . The whipping correspondence began some two years after the opening of the tightlacing controversy, dominating the correspondence until its removal to a Supplemental Conversazione in 1870. Both debates garnered substantial attention from an audience beyond the typical readership, as some letters incorporated sensational elements of sadomasochism, voyeurism, and depictions of dominance and power. These expressions of desire, pain, and pleasure would subsume the conversazione and make it a point of national interest and controversy ${ }^{80}$ According to Beetham, the debates invoked "the multiple and contradictory meanings of [the] female body itself," as fashions like corsets constructed the "female body as erotic surface, as beautiful object" trained via elements of the toilette. ${ }^{81}$ But these discussions 
were not only linked to wearable fashions; they developed from mundane conversations about beauty and bodily self-fashioning that forged a discursive space for the explosive debates to occur.

Although the corset first appeared in the correspondence column in 1865, it sparked more significant discussion in early 1867 when "a lady, dating from Edinburgh" wrote to complain of her daughter's diminished waist size. According to the mother, this transformation occurred when her daughter left British shores to attend an overseas boarding school. The lady described the "torture" her daughter experienced and her change from "a merry romping girl" to a young woman with "murdered" physiology. ${ }^{82}$ A respondent signed "Staylace" accused the mother of "overdrawing" her daughter's "tortures," arguing that she herself "never [felt] prouder or happier" than when laced in her stays. ${ }^{83}$ These letters established the tone and boundaries for the subsequent exchange, as correspondents contested and concurred with others' views. Letters of this sort on tight-lacing would appear intermittently until 1877, dispersed among more mundane queries and echoing disputes about the health effects of fashion and beauty. ${ }^{84}$

By the end of 1867 a new, absorbing discussion on the corporal punishment or flagellation of children subsumed the waist-training debates. ${ }^{85}$ The correspondence began somewhat innocuously with a two-line letter from a "Young Mother" who requested "a few hints" from skilled correspondents (and presumably other mothers) "on the early education and discipline of children." ${ }^{, 86}$ An "Anxious Mother" responded in the next edition with a list of suggestions, having raised "four children, the eldest eight years old." ${ }^{87}$ Replying that a mother "be gentle, never passionate," it was her belief that "whipping should be resorted to very seldom, and only for great offences" that prompted the response of further contributors. ${ }^{88}$ The debate between pro- and anti-rod readers quickly escalated; by December 1868 the letters consumed six 
columns of the magazine per issue. ${ }^{89}$ Beeton attempted to close the debate in January 1869 after scathing criticism from publications like Punch and the Saturday Review, which accused him of profiting from the indecency of the debates. He disputed accusations that he had forged the letters, defending the "fairness" of the correspondence. ${ }^{90}$ The whipping debate reappeared in the Englishwoman's Domestic Magazine in November 1869 and would dominate the conversazione for the next five months. ${ }^{91}$

Despite the sensational and protracted nature of the tight-lacing and whipping debates, they shared analogous features with the mundane letters on health and beauty. In the sensational correspondence, Beeton stayed true to the conversazione as representative of a liberal tradition of open dialogue. Despite being an opponent of both tight-lacing and birching, Beeton refused to censure the sensationalism of the letters. "This irrepressible subject," he wrote of the corset debates, "will make itself heard," adding that "some of the letters received have been found too interesting to discard, unprinted." ${ }^{92}$ Out of dedication to liberal dialogue, compounded by his own curiosity, he rarely intervened or inserted his editorial voice beyond attempts to discontinue the debates in January 1869 (and this only when they virtually incapacitated the conversazione).

As in the mundane correspondence, sensational participants discussed available commercial options, particularly in letters on corsetry. As Boardman argues, a significant element of the corset debate was its focus on a commodity; in this regard, it could not exist independent of broader processes of commercialization playing out in the Englishwoman's Domestic Magazine. ${ }^{93}$ This is clear in some letters, like that of H. W. who held that one could achieve "smallness of girth" in "the easiest and safest mode" by procuring an "accurately-fitting corset." ${ }^{" 94}$ Such beliefs subsequently garnered serious interest in the various styles of corsets available to women. For instance, Mrs. Wray asked to be "informed as to the best place" to find 
"good shaped French corsets," while X. Y. Z. vouched for her favorite brand, "Messrs. Thomson's new glove-fitting corset," which she could not "speak of too highly ... or recommend too strongly. ${ }^{, 95}$ An interest in commercial products also surfaced in the whipping debates, albeit in an almost parodic sense. As with beauty products, correspondents recounted how they produced their own implements of punishment. As "in cases where birch rods are not at hand," one correspondent recommended "a strap of pliable leather, about two feet long ... and inch wide, and an eighth of an inch thick. ${ }^{96}$ Alternatively, correspondents suggested commercial providers, such as a certain manufacturer who would create a device "on receipt of $2 \mathrm{~d}$. or $3 \mathrm{~d}$. per birch rod, of course not paying the carriage."97

Despite these parallels between the mundane and sensational correspondence, there were also important points of divergence. For one, contributors to the mundane beauty correspondence typically participated as self-fashioning subjects asking questions for their own benefit (except for one point in 1866 when Beeton cheekily praised the selflessness of "so many friends" writing to the column "on account of their friends"). ${ }^{98}$ In contrast, the discussions of tight-lacing and whipping were framed as letters from anxious mothers invested in the fashioning (and disciplining) of their daughters. M. C., for example, wrote that she "did not neglect to train the figures of [her] own children," suggesting that readers "take [their] daughters to a first-rate corset maker at once. ${ }^{, 99}$ Maternal control was even more pronounced in the whipping debates where some correspondents transcended their individual bodily selfhood; daughters' bodies, in such cases, often became the site of manipulation and restraint. In thanking correspondents "for so much valuable information...with regard to the discipline of [her] unruly daughter," correspondent "An English Mamma" highlighted reoccurring elements in contributions from pro-rod mothers. ${ }^{100}$ She described a lack of "success" before "receiv[ing] the September number 
of the Englishwoman's Domestic Magazine." ${ }^{101}$ Having "followed [the] advice implicitly" and issued "the semblance of a 'good sound whipping,"” she noted, "the effect...was magical."102

The popularity (or some would argue notoriety) of discussions about tight-lacing and whipping attracted a more heterogeneous group of participants in the conversazione. This was especially the case from 1867, when the column increasingly featured contributions from selfproclaimed outsiders and male correspondents. Participants like "An Old Soldier," who described himself as an "old man of seventy-nine years of age," were certainly not the typical conversazione reader. ${ }^{103}$ Not only did self-identifying male correspondents respond, but they also reprimanded. "My whole blood boils, as an Englishman," wrote Captain R. A., "to read the filthy indecencies described by women calling themselves ladies, but who in reality can be nothing less than she-wolves. ${ }^{, 104}$ Some recognized their perhaps unwelcome interference in a feminine forum. "Being a man," wrote one contributor, "I, of course, ought never to see what your friends say," but he proceeded to note, "if women will publish they must take the consequences."105 Another contributor signed "Materfamilias" observed that ultimately, women were "not very prominent" in the whipping conversation in particular, as outsiders usurped the column from the expected audience of middle-class women. ${ }^{106}$

This did not go unacknowledged among female correspondents. Some readers openly accused contributors to the sensational debates of being male "imposters" who undermined their exclusive forum for debating issues of middle-class femininity under the pretenses of "a feigned name and character." ${ }^{107}$ The result, argues Beetham, destabilized the conversazione more generally, as "the legitimate reader and the illegitimate voyeur were [now] indistinguishable."108 This exposed the seemingly secluded feminine forum, crafted by Beeton and readers alike, to the prying eyes and spurious attention of a masculine public. These intruders threatened to disrupt 
the community of textual participants, which was now monitored by those with seemingly individual rather than collective purposes.

Many letters betrayed a sense of estrangement over this turn, as correspondents felt that the same women traditionally involved in the mundane correspondence were now incapable of participating in such "revolting indecency." ${ }^{109}$ E. K. K., who was "shocked" by the "sentiments of many of the writers," opined that they "certainly do not profit by the otherwise sensible, moral and elegant literature contained in the Magazine." ${ }^{\prime 10}$ Another correspondent expressed dismay at having "been advised to transfer my subscription on account of certain letters (which seem to get worse and worse) frequently appearing in the Conversazione." ${ }^{111}$ Another asserted that the Englishwoman's Domestic Magazine, "until now the best of its class," was now "unfit for any modest person to read."112 The presence of male interlopers threatened not only the column's status as a feminine forum but also the gendered propriety of the magazine itself. Once a respectable title signaling a woman's middle-class feminine values, the Englishwoman's Domestic Magazine and its conversazione were now ambiguously connected to debased interests.

Women readers' distress over this change highlights the conversazione as a site of mundane yet significant discussions of the middle-class female body. Yet the distortion of the conversazione could not have occurred without the mundane beauty correspondence that preceded and paralleled it, for those exchanges established a discursive repertoire out of which the more sensational discussions emerged. Through its mundane discussions of the female body, the conversazione laid the foundations for the more sensational correspondence and its intensified form of discursive exchange. This was an alienating turn for some readers, who saw it as the destruction of their reassuring forum for textual negotiations of and conversations about 
the body. Correspondents attributed this development to interlopers, questioning the gender, class, and moral fiber of sensational contributors, thereby situating them outside the expected composition of the textual community. No such accusations appeared prior to the sensational debates, as correspondents carefully regulated bodily descriptions to avoid charges of immodesty. Only when the debates reached an acute level of bodily manipulation, stoking the interest of those outside the middle-class female community, did readers complain about the content of the column.

\section{Conclusion}

Readers' complaints seem to have been heeded, as Samuel Beeton carefully removed the sensational debates without losing the interest — and income - generated by their salacious content. With the continued influx of letters and the support of publishers Ward, Lock, and Tyler, Beeton produced a separate publication, the Supplemental Conversazione. Appearing from April to December 1870 at a cost of two pence, the eight- to sixteen-page supplement appeared in the same format as the standard conversazione but addressed only one topic: corporal punishment. ${ }^{113}$ Beeton produced it specifically for readers "anxious to support or follow a discussion which possesses extraordinary interest for so many persons." ${ }^{114}$ Participants interacted in a manner similar to the conversazione, taking pro- or anti-rod positions and frequently contributing more than once. The Supplemental Conversazione successfully expunged the whipping letters from the regular edition of the Englishwoman's Domestic Magazine with the debate proceeding uninterrupted in the new publication. After the supplement was discontinued in December, letters on whipping cropped up sporadically in the magazine until 1874, but the debate did not engender the same interest or length as it had in years prior. The conversazione reverted to its original status as an important site of respectable feminine exchange by restoring 
the established etiquette for discussing and debating the female body. This included enquiries about the more quotidian concerns affecting a seeming majority of readers before, during, and after the sensational debates. Such letters continued until the magazine's final edition in $1879 .{ }^{115}$ By crafting a parallel but distinct forum for the sensational letters, Beeton preserved the conversazione as a forum for issues related to women's roles as mothers, consumers, household managers, but also embodied subjects. Indeed, the nature of the conversazione as a textual community for middle-class women's questions about the management and care of their bodies engendered the possibilities for the protracted considerations of erotic affect and selfhood in the sensational debates. These same debates would, however, undermine the column's role as an important site to negotiate women's quotidian enactments of bodily health, beauty, and artifice. The corset and whipping debates exceeded all previous topics in both affective intensity and public attention, thereby challenging the textual community's established protocols. They subsequently garnered unprecedented public scrutiny due to their sustained attention to eroticized female bodies. This also accounts for the considerable scholarly attention to the sensational debates, often at the expense of equally significant quotidian discussions of the body, which were of deep importance to readers.

Regardless of their sensational content, the corset and whipping debates followed a set of established conventions of discursive networking on beauty and the body in the Englishwoman's Domestic Magazine. Tacit, mundane expressions of beauty and self-fashioning allowed those still bound by conventional expectations of domestic femininity to convey their self-conscious, daily engagement with their bodies without transgressing standards of decorum befitting their social status. Through the conversazione, correspondents shared expressions of bodily selfhood, substantiating the existence of others involved in similar experiences and enactments of 
femininity. In this way, they forged a significant textual presence as a community of interlocutors navigating new ideas about beauty, appearance, and the classed female body.

Brock University

\section{BIBLIOGRAPHY}

Angeloglou, Maggie. A History of Make-Up. New York: Macmillan, 1970.

“Answers," Queen 46 (August 14, 1869): 99.

“Answers," Queen 57 (January 2, 1875): 13.

Auerbach, Jeffrey A. “What They Read: Mid- Nineteenth Century English Women's Magazines and the Emergence of a Consumer Culture." Victorian Periodicals Review 30, no. 2 (1997): 121-40.

Ballaster, Ros, Margaret Beetham, Elizabeth Frazer, and Sandra Hebron. Women's Worlds: Ideology, Femininity and the Woman's Magazine. London: MacMillan, 1991.

Beetham, Margaret. "How I Came to Write A Magazine of Her Own?: Domesticity and Desire in the Woman's Magazine, 1800-1914." Victorian Periodicals Review 50, no. 1 (2017): $238-43$.

-. A Magazine of Her Own? Domesticity and Desire in the Woman's Magazine, 18001914. New York: Routledge, 1996.

__. "Natural but Firm': The Corset Correspondence in the Englishwoman's Domestic Magazine." Women: A Cultural Review 2, no. 2 (1991): 163-67.

_. "Time: Periodicals and the Time of the Now." Victorian Periodicals Review 48, no. 3 (2015): 323-42. 
Beetham, Margaret, and Kay Boardman, eds. Victorian Women's Magazines: An Anthology. Manchester: Manchester University Press, 2001.

Boardman, Kay. ““A Material Girl in a Material World’: The Fashionable Female Body in Victorian Women's Magazines.” Journal of Victorian Culture 3, no. 1 (1998): 93-110.

Chavasse, Pye Henry. Advice to a Wife on the Management of Her Own Health. London: Churchill, 1875.

Clark, Jessica P. The Business of Beauty: Gender and the Body in Modern London. London: Bloomsbury, forthcoming.

—. "Pomeroy v. Pomeroy: Beauty, Modernity, and the Female Entrepreneur in Fin-deSiècle London." Women's History Review 22, no. 6 (2013): 877-903.

Cohen, Deborah. Household Gods: The British and Their Possessions. New Haven: Yale University Press, 2006.

“The Englishwoman's Conversazione.” Englishwoman's Domestic Magazine n.s., 2 (December 1860): 96 .

“The Englishwoman's Conversazione.” Englishwoman's Domestic Magazine n.s., 6 (January 1863): 144 .

“The Englishwoman’s Conversazione.” Englishwoman's Domestic Magazine n.s., 9 (October 1864): 288 .

“The Englishwoman's Conversazione.” Englishwoman's Domestic Magazine n.s. 2, 2 (February 1866): 64

“The Englishwoman's Conversazione." Englishwoman's Domestic Magazine n.s. 2, 2 (March 1866): 96. 
“The Englishwoman's Conversazione.” Englishwoman's Domestic Magazine n.s. 2, 3 (February 1867): 109 .

“The Englishwoman's Conversazione.” Englishwoman's Domestic Magazine n.s. 2, 3 (March 1867): 164 .

“The Englishwoman's Conversazione.” Englishwoman's Domestic Magazine n.s. 2, 3 (April 1867): 220 .

“The Englishwoman’s Conversazione.” Englishwoman's Domestic Magazine n.s. 2, 3 (May 1867): 276 .

“The Englishwoman’s Conversazione.” Englishwoman's Domestic Magazine n.s. 2, 4 (February 1868): 109.

“The Englishwoman's Conversazione.” Englishwoman's Domestic Magazine n.s. 2, 4 (April 1868): 221.

“The Englishwoman’s Conversazione.” Englishwoman's Domestic Magazine n.s. 2, 4 (May 1868): 278.

“The Englishwoman’s Conversazione.” Englishwoman's Domestic Magazine n.s. 2, 5 (July 1868): 53.

“The Englishwoman's Conversazione.” Englishwoman's Domestic Magazine n.s. 2, 5 (August 1868): 109 .

“The Englishwoman’s Conversazione.” Englishwoman’s Domestic Magazine n.s. 2, 5 (September 1868): 166.

“The Englishwoman’s Conversazione.” Englishwoman’s Domestic Magazine n.s. 2, 6 (May 1869): 280.

Freeman, Sarah. Isabella and Sam: The Story of Mrs. Beeton. London: Victor Gollancz, 1977. 
Gibson, Ian. The English Vice: Beating, Sex and Shame in Victorian England and After. London: Gerald Duckworth \& Co., 1979.

"Health and Beauty. V.- - The Hair of the Head." Englishwoman's Domestic Magazine 29 (May 1867): 266.

“The Human Form Divine. Noses.” Englishwoman's Domestic Magazine n.s. 2, 2 (March 1866): 80.

“The Human Form Divine. The Hair.” Englishwoman's Domestic Magazine n.s. 2, 2 (February 1866): 48 .

“The Human Form Divine. The Waist.” Englishwoman's Domestic Magazine n.s. 2, 2 (September. 1866): 272.

Jones, Geoffrey. Beauty Imagined: The History of the Global Beauty Business. New York: Oxford University Press, 2011.

Kling, Rebecca. “'It is Only Colour that you Want': Lady Audley's Secret and Cosmetics as a Discursive Fantasy." Victorian Periodicals Review 50, no. 3 (2017): 560-84.

Kunzle, David. Fashion and Fetishism: A Social History of the Corset, Tight-Lacing, and Other Forms of Body Sculpture in the West. Totowa, NJ: Rowman and Littlefield, 1982.

Langland, Elizabeth. Nobody's Angels: Middle-Class Women and Domestic Ideology in Victorian Culture. Ithaca: Cornell University Press, 1995.

Ledbetter, Kathryn. British Women's Periodicals: Beauty, Civilization, and Poetry. New York: Palgrave Macmillan, 2009.

Loeb, Lori. Consuming Angels: Advertising and Victorian Women. New York: Oxford University Press, 1994. 
Marcus, Sharon. Between Women: Friendship, Desire, and Marriage in Victorian England. Princeton: Princeton University Press, 2007.

Marcus, Steven. The Other Victorians: A Study of Sexuality and Pornography in MidNineteenth-Century England. New York: Basic Books, 1975.

The Mother's Medical Advisor \& Guide for Emergencies. London: Ward and Lock, 1862.

The Mother's Thorough Resource-Book. London: Ward and Lock, 1860.

Ofek, Galia. Representations of Hair in Victorian Literature and Culture. London: Ashgate, 2009.

“Our Address.” Englishwoman's Domestic Magazine 1 (May 1852): 1.

Patton, Cynthia Ellen. “'Not a Limitless Possession': Health Advice and Readers' Agency in The Girl's Own Paper, 1880-1890." Victorian Periodicals Review 45, no. 2 (2012): 111-33.

Peiss, Kathy. Hope in a Jar: The Making of America's Beauty Culture. New York: Metropolitan Books, 1998.

Phegley, Jennifer. Educating the Proper Woman Reader: Victorian Family Literary Magazines and the Cultural Health of the Nation. Columbus: The Ohio State University Press, 2004.

Phegley, Jennifer. Courtship and Marriage in Victorian England. Santa Barbara: Praeger, 2012. Poovey, Mary. Uneven Developments: The Ideological Work of Gender in Mid-Victorian England. Chicago: University of Chicago Press, 1988.

Rappaport, Erika D. Shopping for Pleasure: Women in the Making of London's West End. Princeton: Princeton University Press, 2000.

"Rules for Correspondents." Queen 57 (January 2, 1875): 1.

“Supplemental Conversazione.” Englishwoman's Domestic Magazine n.s. 2, 8 (April 1870): 1.

“Supplemental Conversazione.” Englishwoman’s Domestic Magazine n.s. 2, 8 (May 1870): 1. 
“Supplemental Conversazione.” Englishwoman’s Domestic Magazine n.s. 2, 9 (July 1870): 1.

“Supplemental Conversazione.” Englishwoman's Domestic Magazine n.s. 2, 9 (August 1870): 1.

“Supplemental Conversazione.” Englishwoman’s Domestic Magazine n.s. 2, 9 (September 1870): 1 .

“Supplemental Conversazione.” Englishwoman's Domestic Magazine n.s. 2, 9 (October 1870): 1.

Ward, Megan. “'A Charm in Those Fingers': Patterns, Taste, and the Englishwoman's Domestic Magazine." Victorian Periodicals Review 41, no. 3 (2008): 248-69.

Warren, Lynne. “'Women in Conference': Reading the Correspondence Columns in Woman 1890-1910." In Nineteenth-Century Media and the Construction of Identities, edited by Laurel Brake, Bill Bell, and David Finkelstein, 122-34. London: Palgrave, 2001. White, Cynthia L. Women's Magazines 1693-1968. London: Michael Joseph, 1970.

\section{NOTES}

This research was generously supported by the Social Sciences and Humanities Research Council of Canada. I would like to thank Judith Walkowitz, anonymous readers, and members of the Johns Hopkins European History Seminar for their close reading of earlier versions of this essay.

1 “The Englishwoman's Conversazione," Englishwoman's Domestic Magazine n.s. 2, 4 (Feb. 1868): 109 . 
2 “The Englishwoman's Conversazione," Englishwoman's Domestic Magazine n.s. 2, 4 (May 1868): 278.

${ }^{3}$ Beetham mobilizes the work of Benedict Anderson in her conceptualization of textual communities (A Magazine of Her Own, 209). For elaboration on this, see also Beetham, "Time: Periodicals and the Time of the Now," 337, and Warren, "Women in Conference,"” 123-24.

${ }^{4}$ For an overview of the sensational correspondence see Marcus, The Other Victorians.

${ }^{5}$ Poovey, Uneven Developments, 12.

${ }^{6}$ Kunzle, Fashion and Fetishism, xvii-xxi and 41-43.

${ }^{7}$ Ballaster et al., Women's Worlds, 90-91.

${ }^{8}$ See Beetham, A Magazine of Her Own, chapters 5-7, and Marcus, Between Women, chapter 3.

${ }^{9}$ Beetham, A Magazine of Her Own, 62-64. For insights into this formative research, see

Beetham, "How I Came to Write A Magazine of Her Own?"

${ }^{10}$ On Victorian consumption and gender, see Loeb, Consuming Angels, and Rappaport, Shopping for Pleasure, especially 4-5.

${ }^{11}$ Warren, “"Women in Conference,"” 123.

${ }^{12}$ Ballaster et al., Women's Worlds, 5.

${ }^{13}$ Ballaster et al., Women's Worlds, 85.

${ }^{14}$ Ballaster et al., Women's Worlds, 84.

${ }^{15}$ Auerbach, "What They Read," 122-23.

${ }^{16}$ White, Women's Magazines, 44.

17 “Our Address,” Englishwoman's Domestic Magazine 1 (May 1852): 1. 
${ }^{18}$ For more on one such publication, the Queen, see Beetham, A Magazine of Her Own, 89-111, and Rappaport, Shopping for Pleasure, 111-22.

${ }^{19}$ White, Women's Magazines, 44. See also Ward, "'A Charm."”

${ }^{20}$ Beetham, A Magazine of Her Own, 60, and Cohen, Household Gods, 13.

${ }^{21}$ Cohen, Household Gods, xi-xvii and 13.

${ }^{22}$ Beetham, A Magazine of Her Own, 59.

${ }^{23}$ Beetham, A Magazine of Her Own, 65-66. See also Langland, Nobody's Angels, 24-61.

${ }^{24}$ On conceptions of a maternal instinct in the mid-nineteenth century, see Poovey, Uneven

Developments, 7-9, and Langland, Nobody's Angels.

${ }^{25}$ Chavasse, Advice to a Wife, 7.

${ }^{26}$ Beetham, A Magazine of Her Own, 145.

${ }^{27}$ On rhetorics of women's health in the late nineteenth century, see Patton, "Not a Limitless Possession."”

28 “The Human Form Divine. The Waist," Englishwoman's Domestic Magazine n.s. 2, 2 (Sept. 1866): 272 .

29 “The Human Form Divine. Noses," Englishwoman's Domestic Magazine n.s. 2, 2 (Mar. 1866): 80 .

30 “The Human Form Divine. The Hair,” Englishwoman's Domestic Magazine n.s. 2, 2 (Feb. 1866): 48 .

${ }^{31}$ On hair, class, and gender, see Ofek, Representations of Hair.

32 "Health and Beauty. V.- The Hair of the Head," Englishwoman's Domestic Magazine n.s. 2, 3 (May 1867): 266. 
33 "Health and Beauty. V.- The Hair of the Head," Englishwoman's Domestic Magazine n.s. 2, 3 (May 1867): 266.

34 “Health and Beauty. V.- The Hair of the Head," Englishwoman's Domestic Magazine n.s. 2, 3 (May 1867): 266.

35 "Health and Beauty. V.—The Hair of the Head," Englishwoman's Domestic Magazine n.s. 2, 3 (May 1867): 266.

36 "Health and Beauty. V.—The Hair of the Head," Englishwoman's Domestic Magazine n.s. 2, 3 (May 1867): 264.

${ }^{37}$ Kling, “"It is Only Colour,"” 652.

${ }^{38}$ Beetham, A Magazine of Her Own, 71.

${ }^{39}$ Beetham, A Magazine of Her Own, 81-88.

${ }^{40}$ Phegley, Courtship and Marriage, 74; “The Englishwoman's Conversazione,"

Englishwoman's Domestic Magazine n.s., 6 (Jan. 1863): 144.

${ }^{41}$ Beetham, A Magazine of Her Own, 82-83.

${ }^{42}$ Beetham, A Magazine of Her Own, 69.

${ }^{43}$ See, for example, “Answers," Queen, 46 (14 August 1869): 99.

${ }^{44}$ Kunzle, Fashion and Fetishism, 218-22; "Rules for Correspondents," Queen 57 (2 Jan. 1875):

1.

45 “Answers,” Queen, 57 (2 Jan. 1875): 13.

46 “The Englishwoman's Conversazione,” Englishwoman's Domestic Magazine n.s. 2,4 (Feb. 1868): 109.

47 “The Englishwoman's Conversazione,” Englishwoman's Domestic Magazine n.s., 6 (Jan. 1863): 144. 
${ }^{48}$ Warren, "“Women in Conference,"” 123.

49 “The Englishwoman's Conversazione,” Englishwoman's Domestic Magazine n.s. 2, 3 (Feb. 1867): 109.

50 “The Englishwoman's Conversazione," Englishwoman's Domestic Magazine n.s. 2, 3 (Feb. 1867): 109.

${ }^{51}$ A survey of the Englishwoman's Domestic Magazine between June 1860 and March 1867 (the launch of the corset controversy) shows that questions about the body featured in fifty out of eighty-one conversaziones. Bodily questions per column ranged from one to seven.

52 “The Englishwoman's Conversazione,” Englishwoman's Domestic Magazine n.s., 9 (Oct. 1864): 288.

53 “The Englishwoman's Conversazione," Englishwoman's Domestic Magazine n.s. 2, 4 (Feb. 1868): 109.

54 “The Englishwoman's Conversazione,” Englishwoman's Domestic Magazine n.s. 2, 4 (Feb. 1868): 109.

55 “The Englishwoman's Conversazione,” Englishwoman's Domestic Magazine n.s. 2, 4 (Feb. 1868): 109.

56 “The Englishwoman's Conversazione,” Englishwoman's Domestic Magazine n.s. 2, 6 (May 1869): 278.

57 “The Englishwoman's Conversazione,” Englishwoman’s Domestic Magazine n.s. 2, 5 (Sept. 1868): 166.

58 “The Englishwoman's Conversazione,” Englishwoman's Domestic Magazine n.s. 2, 5 (Jul. 1868): 53. 
59 “The Englishwoman's Conversazione,” Englishwoman's Domestic Magazine n.s. 2, 5 (Aug. 1868): 109.

60 “The Englishwoman's Conversazione,” Englishwoman's Domestic Magazine n.s. 2, 5 (Aug. 1868): 109.

${ }^{61}$ Ledbetter, British Women's Periodicals, 134.

62 “The Englishwoman's Conversazione," Englishwoman's Domestic Magazine n.s. 2, 5 (Jul. 1868): 53.

63 “The Englishwoman's Conversazione,” Englishwoman's Domestic Magazine n.s. 2, 4 (Feb. 1868): 109.

64 “The Englishwoman's Conversazione,” Englishwoman’s Domestic Magazine n.s., 2 (Dec. 1860): 96; italics in the original.

65 “The Englishwoman's Conversazione,” Englishwoman’s Domestic Magazine n.s., 2 (Dec. 1860): 96.

${ }^{66}$ Though many historians have studied aspects of Victorian fashion, there remains work to be done on beauty culture and cosmetic use in nineteenth-century Britain. See Angeloglou, $A$ History of Make-Up, Clark, The Business of Beauty, Clark, "Pomeroy v. Pomeroy," and Kling, “"It is Only Colour."” For global contexts see Jones, Beauty Imagined, and Peiss, Hope in a Jar. 67 “The Englishwoman's Conversazione,” Englishwoman's Domestic Magazine n.s. 2, 4 (Apr. 1868): 221; italics in the original.

68 “The Englishwoman's Conversazione,” Englishwoman's Domestic Magazine n.s. 2, 3 (Apr. 1867): 220 .

69 “The Englishwoman's Conversazione," Englishwoman's Domestic Magazine n.s. 2, 4 (Apr. 1868): 221. 
70 “The Englishwoman's Conversazione," Englishwoman's Domestic Magazine n.s. 2, 4 (Apr. 1868): 221.

71 “The Englishwoman's Conversazione,” Englishwoman's Domestic Magazine n.s. 2, 4 (Apr. 1868): 221.

72 “The Englishwoman's Conversazione,” Englishwoman's Domestic Magazine n.s. 2, 4 (May 1868): 278.

${ }^{73}$ Auerbach, "What They Read," 132.

${ }^{74}$ Phegley, Educating the Proper Woman Reader, 15.

${ }^{75}$ Boardman, “A Material Girl in a Material World,"” 100-101.

76 “The Englishwoman's Conversazione,” Englishwoman's Domestic Magazine n.s. 2, 4 (Apr. 1868): 221.

77 “The Englishwoman's Conversazione,” Englishwoman's Domestic Magazine n.s. 2, 4 (Apr. 1868): 221.

78 “The Englishwoman's Conversazione,” Englishwoman's Domestic Magazine n.s. 2, 2 (Feb. 1866): 64; and “The Englishwoman’s Conversazione," Englishwoman's Domestic Magazine n.s. 2, 4 (Feb. 1868): 109.

${ }^{79}$ For more on advertising for women in this period, see Loeb, Consuming Angels.

${ }^{80}$ Beetham, A Magazine of Her Own, 72.

${ }^{81}$ Beetham, A Magazine of Her Own, 84, 88.

82 “The Englishwoman's Conversazione," Englishwoman's Domestic Magazine n.s. 2, 3 (Mar. 1867): 164. See also Beetham, "'Natural but Firm."” Other letters in this edition addressed chignons, diets, exercise, and bathing. 
83 “The Englishwoman's Conversazione," Englishwoman's Domestic Magazine n.s. 2, 3 (Apr. 1867): 220. Also quoted in Beetham, "“Natural but Firm,"” 164.

${ }^{84}$ Beetham, A Magazine of Her Own, 72.

${ }^{85}$ Gibson, The English Vice, 219.

86 “The Englishwoman's Conversazione," Englishwoman's Domestic Magazine n.s. 2, 3 (Feb. 1867): 109.

87 “The Englishwoman's Conversazione," Englishwoman's Domestic Magazine n.s. 2, 3 (Mar. 1867): 164.

88 “The Englishwoman's Conversazione," Englishwoman's Domestic Magazine n.s. 2, 3 (Mar. 1867): 164.

${ }^{89}$ Gibson, The English Vice, 221.

90 “The Englishwoman's Conversazione,” Englishwoman's Domestic Magazine n.s. 2, 6 (Jan. 1869): 52.

${ }^{91}$ Freeman, Isabella and Sam, 274, and Gibson, The English Vice, 223-24.

92 “The Englishwoman's Conversazione,” Englishwoman's Domestic Magazine n.s. 2,4 (Feb. 1868): 109; italics in the original.

${ }^{93}$ Boardman, "A Material Girl in a Material World," 105.

94 “The Englishwoman's Conversazione,” Englishwoman's Domestic Magazine n.s. 2, 3 (May 1867): 276.

95 “The Englishwoman's Conversazione,” Englishwoman's Domestic Magazine n.s. 2, 4 (Feb. 1868): 109; italics in the original; “The Englishwoman's Conversazione," Englishwoman's Domestic Magazine n.s. 2, 3 (May 1867): 276.

96 “Supplemental Conversazione,” Englishwoman's Domestic Magazine n.s. 2, 8 (May 1870): 1. 
97 “Supplemental Conversazione,” Englishwoman's Domestic Magazine n.s. 2, 8 (May 1870): 1.

98 “The Englishwoman's Conversazione,” Englishwoman's Domestic Magazine n.s. 2, 2 (Mar. 1866): 96; italics in the original.

99 “The Englishwoman's Conversazione,” Englishwoman's Domestic Magazine n.s. 2, 4 (Apr. 1868): 221.

100 “The Englishwoman’s Conversazione,” Englishwoman's Domestic Magazine n.s. 2, 5 (Oct. 1868): 220 .

101 “The Englishwoman's Conversazione,” Englishwoman's Domestic Magazine n.s. 2, 5 (Oct. 1868): 220 .

102 “The Englishwoman’s Conversazione,” Englishwoman’s Domestic Magazine n.s. 2, 5 (Oct. 1868): 220 .

103 “Supplemental Conversazione," The Englishwoman's Domestic Magazine n.s. 2, 9 (July 1870): 1 .

104 “Supplemental Conversazione," The Englishwoman's Domestic Magazine n.s. 2, 9 (August 1870): 1; italics in the original.

105 “Supplemental Conversazione," The Englishwoman's Domestic Magazine n.s. 2, 9 (October 1870): 1 .

106 “Supplemental Conversazione,” The Englishwoman's Domestic Magazine n.s. 2, 9 (July 1870): 1 .

107 “Supplemental Conversazione,” The Englishwoman's Domestic Magazine n.s. 2, 9 (July 1870): 1 .

${ }^{108}$ Beetham, A Magazine of Her Own, 86. 
109 “Supplemental Conversazione,” The Englishwoman's Domestic Magazine n.s. 2, 9 (July 1870): 1 .

110 “Supplemental Conversazione," The Englishwoman's Domestic Magazine n.s. 2, 9 (September 1870): 1.

111 “Supplemental Conversazione,” The Englishwoman's Domestic Magazine n.s. 2, 8 (April 1870): 1 .

112 "Supplemental Conversazione," The Englishwoman's Domestic Magazine n.s. 2, 9 (August 1870): 1 .

${ }^{113}$ Gibson, The English Vice, 226.

114 “Supplemental Conversazione,” Englishwoman's Domestic Magazine n.s. 2, 8 (April 1870):

1.

${ }^{115}$ Beetham and Boardman, Victorian Women's Magazines, 32. 